\title{
Experimental Study on Thermal Performance of Externally Insulated Walls of Intermittent Air-Conditioned Rooms in Summer in Hot Summer and Cold Winter Region, China
}

\author{
Yong Ding, ${ }^{1,2}$ Lu Xu, ${ }^{1,2}$ Baizhan Li, ${ }^{1,2}$ and Xiaoqing Liu ${ }^{1,2}$ \\ ${ }^{1}$ Faculty of Urban Construction and Environmental Engineering, Chongqing University, Chongqing 400045, China \\ ${ }^{2}$ China Key Lab of Three Gorges Reservoir Region's Eco-Environment, Chongqing University, Ministry of Education, \\ Chongqing 400045, China \\ Correspondence should be addressed to Yong Ding; dingyongqq@163.com
}

Received 23 March 2014; Accepted 30 July 2014; Published 20 August 2014

Academic Editor: Sanjeeviraja Chinnappanadar

Copyright @ 2014 Yong Ding et al. This is an open access article distributed under the Creative Commons Attribution License, which permits unrestricted use, distribution, and reproduction in any medium, provided the original work is properly cited.

\begin{abstract}
Now requirements for the thermal performance of building walls are based on the assumption that heat flux transfers in one direction through the wall. However, in Hot Summer and Cold Winter Region of China, the direction of heat flow in the wall not only changes with the seasons, but also changes in the same period of using. In this paper, dynamic thermal process of externally insulated walls in different air-conditioner's running state in summer in Chongqing, China, was tested. The distribution characteristics of the outdoor and indoor air temperature and the surface and inner temperatures of the wall were analyzed and demonstrated. Based on the unsteady-state heat transfer theory, the study calculated and analyzed the distribution characteristics of the direction of the heat flux in the thermal process. Also the characteristics of insulation and heat preservation for walls under different air-conditioner's running state were analyzed. It is shown that, in any air-conditioner's running state, the direction of the heat flux through the wall is obviously dynamically changing. There is obvious difference in the thermal performance needs of the wall; that is, it has strong demand for thermal insulation in daytime and strong demand for heat dissipation during night time in summer.
\end{abstract}

\section{Introduction}

Walls of the building envelope play an important role in the heat transfer between the exterior and the interior spaces of the building. From a thermal point of view, a wall of good thermal performance is one that contributes to thermal comfort conditions inside the building without using heating or cooling air-conditioning systems or using them with minimum energy consumption. At present studies about heat preservation for external walls in northern China have been very common. In this paper, interest is focused on the dynamic process of the heat flux and requirements of thermal performance of walls in summer in Hot Summer and Cold Winter Region, China. Results of this work can provide basis for building wall energy saving design in this region.

It is scorching and burning hot in summer in Hot Summer and Cold Winter Region in China. The mean air temperature in hottest month is $26.5-30.5^{\circ} \mathrm{C}$ and the extreme high temperature is above $42^{\circ} \mathrm{C}$. The solar-air temperature in horizontal plane can reach $60^{\circ} \mathrm{C}$ [1]. With strong solar radiation and high diurnal ambient temperature in the daytime in summer, the outdoor surface temperatures of the external walls are higher than the indoor surface temperatures, so as to form a heat flow transferring through the wall from the outside to the inside. During night time when solar radiation is no longer present and temperature of ambient air declines, the temperature difference between the indoor and outdoor environment changes, so that the direction of the heat flux through the wall will be changed [2-5]. The dynamic heat transfer process through the wall caused by the vector changes of the indoor and outdoor temperature difference is different from the thermal process of the wall in cold regions in China $[6,7]$. Therefore, optimizing the configurations for insulation and heat preservation of the wall in this region should be based on the dynamic changing process of heat flux through walls, so as to make the wall fit to needs of 
different indoor thermal environment and maximum meet the requirements of insulation and heat dissipation of the wall. It is the key for the study of building wall energy savings in Hot Summer and Cold Winter Region. And it differs from the study features of cold regions that merely have emphasis on heat preservation.

In Hot Summer and Cold Winter Region, due to the occupants' long-term behaviors, they mainly developed a habit of intermittent use of air-conditioner for cooling or heating whether in summer or in winter $[8,9]$. According to the research results of the "Eleventh Five-Year National Science and Technology Support Program," in this region, when in summer, 42.3 percent of the investigation objects would use air-conditioner during the night, 27.7 percent in the afternoon, while others would use air-conditioner at noon; besides, in summer, 67.2 percent of the investigation objects would use air-conditioners continuously and 32.8 percent would use the air-conditioner intermittently. It can be seen that vast majority of the occupants would only use air-conditioning systems when it is burning hot and they are in the room. In addition, they use air-conditioners intermittently.

In such an outdoor thermal environment and intermittent operating condition of the air-conditioning system, what kind of dynamic changing process will the indoor thermal environment present? And how does the direction of the heat flux in the wall change? The discussion about these issues is related to the point about what requirements should the configuration for a wall meet when designing the energy saving walls for this region.

The aim of this work is to analyze the dynamic process of heat flux through the wall of intermittent air-conditioned rooms and different requirements of thermal performance of the wall under different conditions in summer in this region and provide basis for designing the configurations for walls in this region. In order to achieve the aim of the work, the on-site field measurement of the thermal process of the wall in summer was carried out in a laboratory building in Chongqing, China.

\section{Methods}

Now there is limited research about the thermal processes of the wall of intermittent air-conditioned rooms in Hot Summer and Cold Winter Zone of China. In order to study the heat transfer process through the wall in this region, the on-site field measurement of the thermal process of the wall was carried out in a laboratory building in Chongqing, China. The west external wall in the testing room is externally insulated. The main body material of the wall is ordinary sintered shale hollow brick $(190 \mathrm{~mm} \times 240 \mathrm{~mm}$ $\times 115 \mathrm{~mm}$ ), and the insulation material is burning level grade $\mathrm{A}$ vitrified microsphere inorganic thermal insulation mortar $(30 \mathrm{~mm})$. The thermal transmittance $(K$-value $)$ of the wall is $1.186 \mathrm{~W} /\left(\mathrm{m}^{2} \cdot \mathrm{K}\right)$ and the index of thermal inertia $(D$ value) is 1.65 (the $D$-value of the wall is a dimensionless quantity that is often used to describe the ability to resist temperature fluctuations of building envelope), which meet

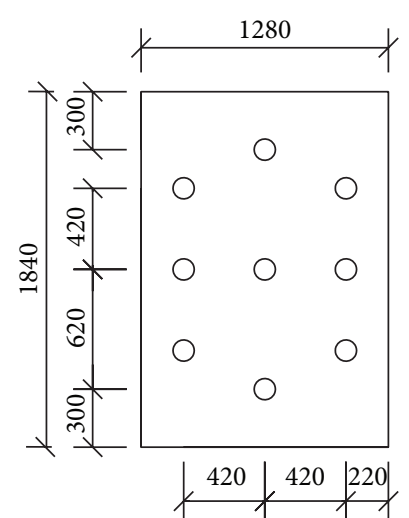

FIGURE 1: Dimension of the externally insulated wall and location of the thermocouple sensors.

the requirements of Design standard for energy efficiency $65 \%$ of residential building in Chongqing area [10].

Each testing point was located in accordance with the requirements of the relevant testing standards [11-14]. Type $\mathrm{T}$ thermocouple sensors with a measurement error of $\pm 0.1^{\circ} \mathrm{C}$ were installed uniformly on the outdoor surface and the indoor surface of the wall and embedded in the contact layer of the insulation material and the main body of the wall for temperature measurements as shown in Figure 1. In this paper, the contact layer of the insulation material and the main body of the wall is referred to as intermediate layer. According to the heat transfer theory, the heat transfer process of this testing wall can be calculated by one-dimensional heat transfer model, and the calculation error is less than $1 \%$ [15]. Figure 1 shows the location of temperature sensors on the testing wall. There were 9 thermocouple sensors on each layer including one at the center and eight sensors around. All measurements were logged by a data logger at an interval of 3 minutes and were averaged to give $30-\mathrm{min}$ data. A split-type air-conditioner was employed to control the room temperature, with a set-point temperature of $26^{\circ} \mathrm{C}$.

Field tests were conducted in representative days of July and August in Chongqing in order to have tests in typical climate periods [16]. Tests were conducted under three conditions that were as follows: air-conditioner runs continuously throughout the day (that is to say, air-conditioner being on from 0:00 to 24:00 continuously); air-conditioner runs in the daytime (air-conditioner being on from 14:00 to 22:00); and air-conditioner runs during the night (air-conditioner being on from 22:00 to 08:00 of the next day). In each condition, the collected data includes outdoor meteorological parameter, indoor air temperature and humidity, and temperature of the three layers of the wall. On the basis of the results, the dynamic characteristics of the collected data are analyzed. Besides, the characteristics of the indoor thermal environment and the dynamic changing process of the heat flux through the wall are analyzed.

\section{Results and Discussion}

The temperature variations of each testing point during the testing period are displayed in Figures 2-4. According to 


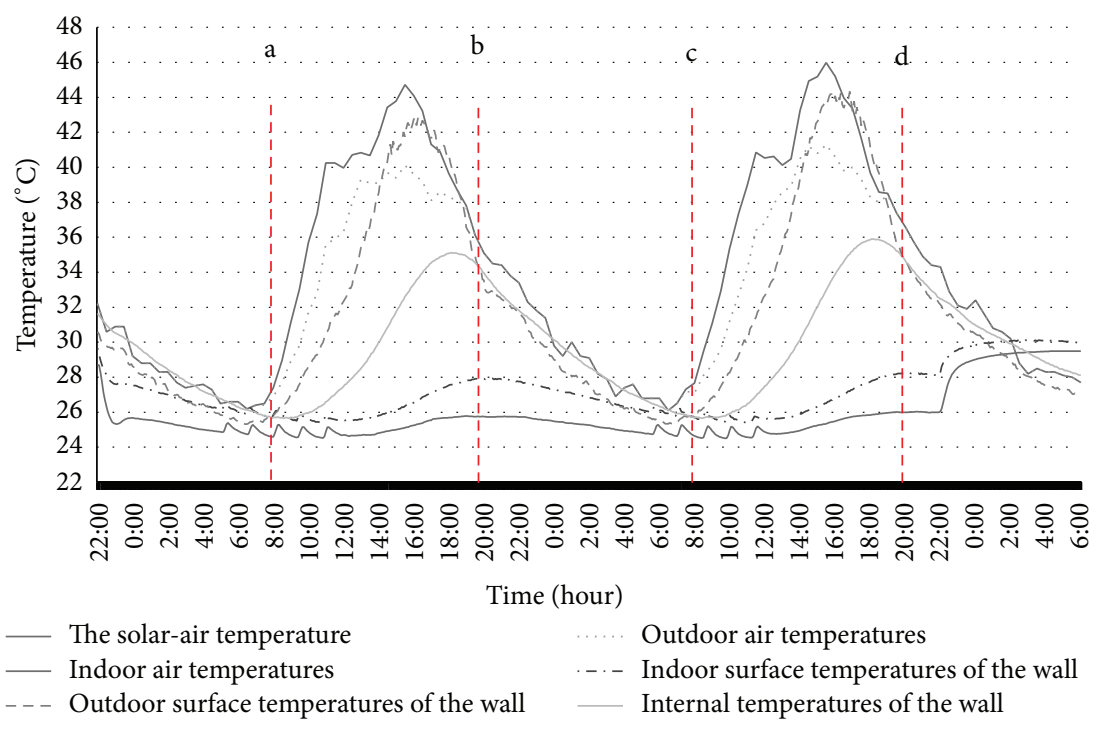

FIGURE 2: Testing-point temperatures of externally insulated wall in continuous running state of air-conditioner.

the data variations and the unsteady-state heat transfer theory, the characteristics of the heat flux directions in the unsteady-state heat transfer process of the wall and heat transfer rate in each direction in different air-conditioner running state are obtained.

3.1. Air-Conditioner Runs Continuously throughout the Day (Air-Conditioner Being on from 0:00 to 24:00). Figure 2 presents the outdoor and indoor air temperatures. During the last 2 days of operation, the outdoor temperature presents a property of daily transient changes. It is low in the morning $\left(26^{\circ} \mathrm{C}\right)$ and rises to nearly $41^{\circ} \mathrm{C}$ at about $15: 30$. Then, the temperature begins to fall. The outdoor air temperature fluctuates largely between 26 and $41^{\circ} \mathrm{C}$ throughout the day. The indoor air temperature remains almost constant (24$26^{\circ} \mathrm{C}$ ) throughout the day with the air-conditioner on.

Figure 2 also presents the variations of the outdoor surface temperatures of the wall and the indoor surface and the intermediate layer temperatures of the wall. It can be seen from the figure that during a-b period (i.e., about 8:0020:00) and c-d period (i.e., 8:00-20:00 in the second day of operation), affected by strong solar radiation and high diurnal ambient temperature, the outdoor surface temperatures of the wall quickly climb to the peak; because of the time lag responses and peak delays of the wall, the outdoor surface temperatures of the wall are the highest, the intermediate layer temperatures of the wall at the middle, and the indoor surface temperatures of the wall the lowest. That is to say, the temperature distribution in the wall is outdoor surface temperatures $>$ the intermediate layer temperatures $>$ indoor surface temperatures. Thus the direction of heat flux in the wall flows from the outside to the inside.

During a-b period in the figure (8:00-20:00), the outdoor surface temperatures of the wall gradually decrease to exactly the same as the temperatures of the intermediate layer. Later, the relative relationship of these two temperatures changes more than before. During b-c period (from about 20:00 to 8:00 of the next day), due to the heat stored in the wall, the temperatures of the intermediate layer are higher than both the outdoor surface and the indoor surface temperatures of the wall which lead to the change of the direction of heat flux through the wall. The heat flux in the wall flows from the internal of the wall to the outdoor surface and the indoor surface of the wall. In addition, according to the temperature variations in the second day of the testing period, this phenomenon is repeatable.

The analysis above indicates that directions of the heat flux are dynamically changing in the state that air-conditioner runs continuously throughout the day. To analyze the characteristics of vector changes in the heat transfer process during each period, the heat transfer rate and ratio of heat flux in each direction are calculated.

Heat transfer process through the wall is a kind of unsteady-state heat transfer process. In accordance with the dimension of the testing wall, its heat transfer process can be calculated by one-dimensional heat transfer model. So the governing equations of this heat transfer process can be expressed by the differential equation of heat conduction which describes the inner temperature distribution in the solids and Fourier's law analytic expression. The equations are presented by [17]

$$
\begin{aligned}
& \frac{\partial t(x, \tau)}{\partial \tau}=a \frac{\partial t^{2}(x, \tau)}{\partial x^{2}}, \\
& q(x, \tau)=-\lambda \frac{\partial t(x, \tau)}{\partial x},
\end{aligned}
$$

where $a=\lambda / c \rho$ is called the thermal diffusivity of the whole wall construction $\left(\mathrm{m}^{2} / \mathrm{s}\right), \lambda$ is the thermal conductivity of the material $(\mathrm{W} / \mathrm{m} \cdot \mathrm{K}), c$ is the specific heat of the material $(\mathrm{kJ} / \mathrm{kg} \cdot \mathrm{K})$, and $\rho$ is the mass density of the material $\left(\mathrm{kg} / \mathrm{m}^{3}\right)$.

According to the governing equations and the given boundary conditions (the air film temperatures of both sides 
of the wall or the change of heat release), the surface or inner layer temperatures of the wall and the heat flux through the wall at any moment can be calculated by finite difference method. The heat flux through each layer of the wall per unit area at any moment $(\mathrm{m})$ can be calculated using

$$
q_{k}^{m}=\frac{2}{\left(\left(\Delta x_{k} / \lambda_{k}\right)+\left(\Delta x_{k+1} / \lambda_{k+1}\right)\right)}\left(t_{k}^{m}-t_{k+1}^{m}\right),
$$

where $\lambda_{k}$ and $\lambda_{k+1}$ are the thermal conductivities of the $k$ th and $(k+1)$ th layers, respectively; $\Delta x_{k}$ and $\Delta x_{k+1}$ are the thickness of the $k$ th and $(k+1)$ th layers, respectively; $t_{k}^{m}$ and $t_{k+1}^{m}$ are the mean temperature of the $k$ th and $(k+1)$ th layers at the moment $m$, respectively.

According to the principle above, the original temperature curves are discretized by the difference methods $[18,19]$ in order to get the heat flux in certain direction during the corresponding period. The discrete time interval is set as $\Delta \tau=10$ minutes, and the amplitude magnitude equals the temperature value of the intermediate moment in each time interval. Therefore, by further calculation, the ratio of heat flux in each direction to the total heat flux in the testing period under the conditions that the air-conditioner runs continuously throughout the day can be obtained as shown in Table 1.

3.2. Air-Conditioner Runs in the Daytime (Air-Conditioner Being on from 14:00 to 22:00). It can be seen from Figure 3 that the outdoor temperature presents a property of daily dynamic changes. In the air-conditioner's running period (12 in the figure) and the outage period (2-c in the figure), the outdoor air temperature fluctuates largely between 28 and $42^{\circ} \mathrm{C}$. However, the indoor air temperature remains almost constant $\left(26-28^{\circ} \mathrm{C}\right)$ in the running period of the airconditioner. After the air-conditioner was turned off, during 2-b period (about 22:00-1:00 of the next day), the indoor air temperature gradually rises to natural room temperature with effect of the outdoor disturbance. And from b (1:00 of the next day) to the following day before the air-conditioner was turned on, the indoor air temperature remains almost constant (about $30^{\circ} \mathrm{C}$ ).

The temperature variations of the outdoor surface, the indoor surface, and the intermediate layer of the wall are displayed in Figure 3. During the air-conditioner's running period, 1-a in the figure (from 14:00 when the air-conditioner was turned on to 19:00 when the temperature of the outdoor surface of the wall is exactly the same as the intermediate layer temperature), outdoor surface temperatures of the wall are the highest and indoor surface temperatures of the wall are the lowest. The temperature distribution in the wall is outdoor surface temperatures $>$ the intermediate layer temperatures $>$ indoor surface temperatures. Thus the heat flux in the wall flows from the outside to the inside.

At point a, the outdoor surface temperatures of the wall are equal to the intermediate layer temperatures. Later, the outdoor surface temperatures of the wall go down, lower than the intermediate layer temperatures. During a-2 period (about 19:00-22:00 when the air-conditioner was off), because the wall stores heat in the daytime, the temperatures
TABLE 1: The ratio of heat flux in each direction to the total heat flux under the conditions that air-conditioner runs continuously throughout the day.

\begin{tabular}{|c|c|}
\hline $\begin{array}{l}\text { The heat flux directions that } \\
\text { occurred during the testing } \\
\text { period }\end{array}$ & $\begin{array}{l}\text { The ratio of heat flux in this } \\
\text { direction to the total heat flux } \\
\text { of the testing period }\end{array}$ \\
\hline $\begin{array}{l}\text { Heat flux from the outside to the } \\
\text { inside }\end{array}$ & $42 \%$ \\
\hline $\begin{array}{l}\text { Heat flux from the internal of the } \\
\text { wall to the outdoor surface and } \\
\text { the indoor surface of the wall }\end{array}$ & $58 \%$ \\
\hline
\end{tabular}

TABLE 2: The ratio of heat flux in each direction to the total heat flux in the state that air-conditioner runs in the daytime.

\begin{tabular}{l}
$\begin{array}{l}\text { The heat flux directions that } \\
\text { occurred during the testing } \\
\text { period }\end{array}$ \\
$\begin{array}{l}\text { Heat flux from the outside to } \\
\text { the inside }\end{array}$ \\
$\begin{array}{l}\text { The ratio of heat flux in this } \\
\text { Heat flux from the internal of } \\
\text { the wall to the outdoor surface } \\
\text { and the indoor surface of the } \\
\text { wall }\end{array}$ \\
$\begin{array}{l}\text { Heat flux from the inside to } \\
\text { the outside }\end{array}$ \\
\hline
\end{tabular}

of the intermediate layer are higher than both the outdoor surface and the indoor surface temperatures. That is to say, the intermediate layer temperatures $>$ outdoor surface temperatures $>$ indoor surface temperatures. The direction of the heat flux in the wall changes from the internal of the wall to the outdoor and indoor surface of the wall.

In 2-b period (from 22:00 when the air-conditioner was turned off to 1:30 of the next day), the direction of the heat flux in the wall keeps unchanged: still from the internal of the wall to the outdoor surface and the indoor surface of the wall. Till point $b$, the indoor surface temperatures of the wall are exactly the same as the intermediate layer temperatures. Later, from point $b$ to $c$ (about 1:30-8:30 on the next day), due to the cooling effect caused by the lower night time temperature, the outdoor surface temperatures of the wall decline; the indoor surface temperatures of the wall are the highest, the intermediate layer temperatures of the wall at the middle, and the outdoor surface temperatures of the wall the lowest. Therefore, the heat flux direction in the wall changes from the inside to the outside.

Similarly, with the finite difference method, the ratio of heat flux in each direction to the total heat flux in the state that air-conditioner runs in the daytime can be calculated as shown in Table 2.

3.3. Air-Conditioner Runs during the Night (Air-Conditioner Being on from 22:00 to 08:00 of the Next Day). It can be seen from Figure 4 that the outdoor air temperature presents a property of daily transient changes. It is low in the morning (about $26^{\circ} \mathrm{C}$ ) and rises to nearly $39^{\circ} \mathrm{C}$ at about $15: 30$. Then it 


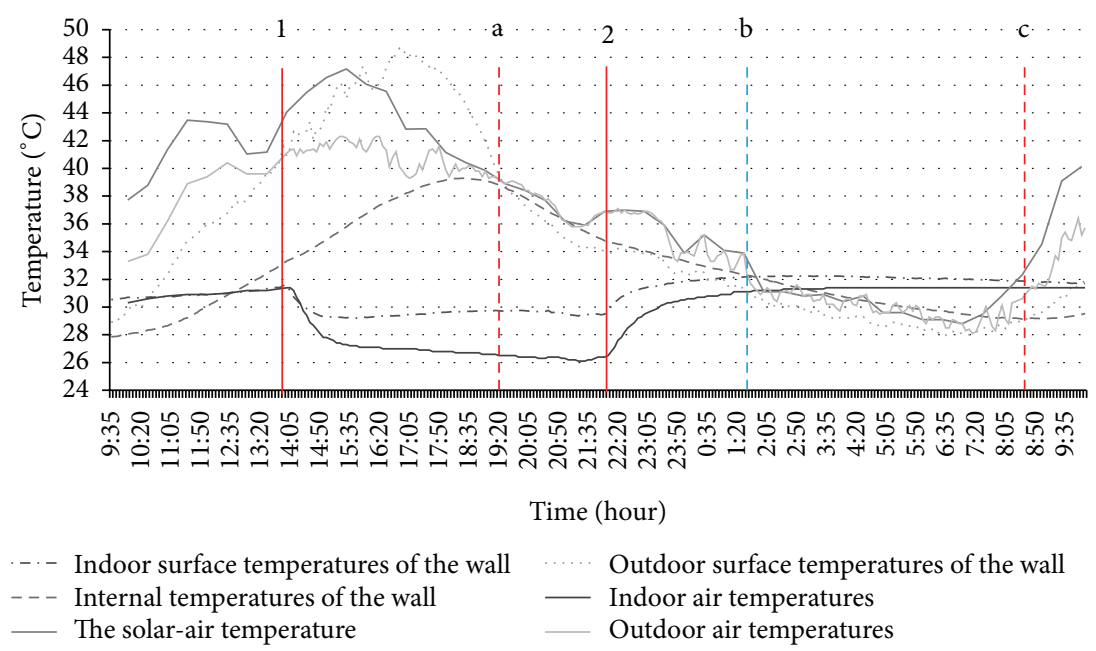

FIGURE 3: Testing-point temperatures of externally insulated wall in daytime running state of air-conditioner.

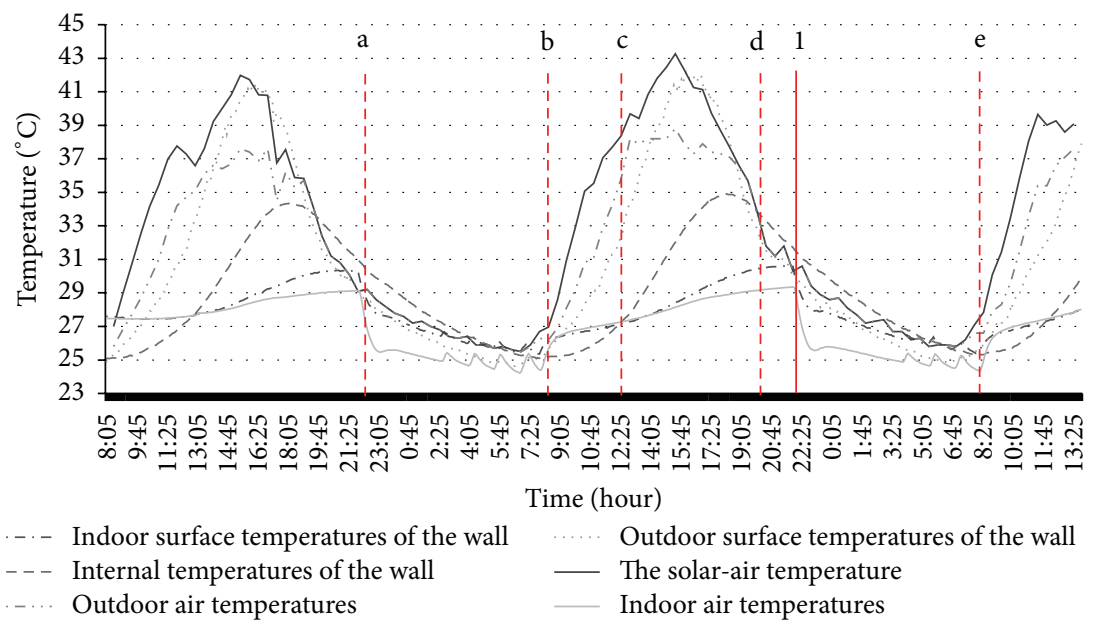

FIGURE 4: Testing-point temperatures of externally insulated wall in night time running state of air-conditioner.

goes down afterwards. The outdoor air temperature ranges from 26 to $39^{\circ} \mathrm{C}$ throughout the day. The indoor temperature plunges within one hour after the air-conditioner was turned on (i.e., 22:00-23:00). And it remains almost constant at approximately $25^{\circ} \mathrm{C}$ during the operation period of airconditioner. During the outage period of the air-conditioner, the indoor air temperature gradually rises to about $29^{\circ} \mathrm{C}$ with action of the outdoor disturbance. It swings between 24 and $29^{\circ} \mathrm{C}$ throughout the day.

Figure 4 depicts the temperature variations of the outdoor surface, the indoor surface, and the intermediate layer of the wall. During the operation period of the air-conditioner, that is, $\mathrm{a}-\mathrm{b}$ (the moment when the air-conditioner was turned on8:00 of the next day turning off the air-conditioner) and 1-e period (22:00 of the next day turning on the air-conditioner8:00 of the third day turning off the air-conditioner) in the figure, because of the heat stored in the wall in the daytime and low ambient temperature in the night time, the temperatures of the intermediate layer are higher than both the outdoor and indoor surface temperatures of the wall. During this period, the heat flux in the wall flows from the internal of the wall to the outdoor surface and the indoor surface of the wall.

After turning off the air-conditioner, during $b-c$ period in the figure (about 8:00 of the next day turning off the airconditioner-13:00 on the next day), that is, from morning to noon, affected by solar radiation, the outdoor and indoor air temperatures begin to go up, respectively. Therefore, both the outdoor surface and the indoor surface temperatures of the wall are higher than the intermediate layer temperatures. The temperature distribution in the wall is outdoor surface temperatures $>$ indoor surface temperatures $>$ the intermediate layer temperatures. The heat flux in the wall flows from the outdoor surface and the indoor surface of the wall to the internal of the wall.

At point $c$ the indoor surface and the intermediate layer temperatures of the wall are equal. Later, the temperatures of the intermediate layer go up, so during c-d period (about 
TABLE 3: The ratio of heat flux in each direction to the total heat flux in the state that air-conditioner runs during the night.

\begin{tabular}{l}
$\begin{array}{l}\text { The heat flux directions that } \\
\text { occurred during the testing } \\
\text { period }\end{array}$ \\
$\begin{array}{l}\text { Heat flux from the internal of the ratio of heat flux in this } \\
\text { direction to the total heat flux } \\
\text { of the testing period }\end{array}$ \\
$\begin{array}{l}\text { wall to the outdoor surface and } \\
\text { the indoor surface of the wall }\end{array}$ \\
$\begin{array}{l}\text { Heat flux from the outdoor } \\
\text { surface and the indoor surface of } \\
\text { the wall to the internal of the wall }\end{array}$ \\
$\begin{array}{l}\text { Heat flux from the outside to the } \\
\text { inside }\end{array}$ \\
$\begin{array}{l}\text { Heat flux from the internal of the } \\
\text { wall to the outdoor surface and } \\
\text { the indoor surface of the wall }\end{array}$ \\
\hline
\end{tabular}

13:00-20:30 on the next day), outdoor surface temperatures $>$ the intermediate layer temperatures $>$ indoor surface temperatures. The heat flux in the wall flows from the outside to the inside.

With the descent of the outdoor air temperature in the night time, the outdoor surface temperatures of the wall gradually decrease. At point d (about 20:30 of the next day), the outdoor surface and the intermediate layer temperatures of the wall are equal. Later, the temperatures of the intermediate layer are higher than both the outdoor surface temperatures and the indoor surface temperatures. Therefore, during $\mathrm{d}-1$ period in the figure (about 20:30-22:00 on the next day), the direction of the heat flux in the wall changes from the internal of the wall to the outdoor surface and the indoor surface of the wall.

Similarly, with the finite difference method, the ratio of heat flux in each direction to the total heat flux in the state that the air-conditioner runs during the night time can be obtained as shown in Table 3.

\section{Conclusions}

The dynamic process of the heat flux through building externally insulated walls of intermittent air-conditioned rooms in summer in Chongqing area, China, was tested. The major conclusions based on the actual data analyses presented are as follows.

(1) The analysis results based on the field measurements show that, because of the climatic conditions and occupants' habits, the heat flux directions through the wall are dynamically changing on any different air-conditioner's running state in summer in this region. For the externally insulated walls, the heat flux through the wall is not in a single direction.

(2) The analysis and calculation results based on the field measurements show that, for the externally insulated wall, the directions of the heat flux through the wall present different dynamic change law in different running state of the air-conditioning system.
(1) When the air-conditioner runs continuously throughout the day, the indoor air temperature keeps lower than the outdoor air temperature; the ratio of heat flux from the outside to the inside to the heat flux from the internal of the wall to the outdoor surface and the indoor surface of the wall stands at $1: 1.4$. These two heat fluxes are almost equal.

(2) In the state that the air-conditioner runs in the daytime, the indoor air temperature is lower than the outdoor air temperature from morning to the midnight while from midnight to the next morning the indoor air temperature becomes higher than the outdoor temperature. The heat flux transferring from the inside to the outside is the minimum; it contributes only $10 \%$ to the total heat flux during the whole testing period under this condition. As to the ratio of the heat flux in other two processes, the ratio of the heat flux from the outside to the inside to the heat flux from the internal of the wall to the outdoor surface and the indoor surface of the wall stands at $1.1: 1$. Also they are almost equal.

(3) When the air-conditioner runs during the night, the indoor air temperature keeps lower than the outdoor air temperature. The heat transfer process through the wall is the most complicated under this state. There are three different heat transfer processes distributed in four stages. The direction of heat flux in each stage is as follows: the heat flux transferring from the internal of the wall to the outdoor surface and the indoor surface of the wall, from the outdoor surface and the indoor surface of the wall to the internal of the wall, and from the outside to the inside and the heat flux from the internal of the wall to the outdoor surface and the indoor surface of the wall. The ratio of the heat flux from the internal of the wall to the outdoor surface and the indoor surface of the wall to the heat flux from the outdoor surface and the indoor surface of the wall to the internal of the wall and the heat flux from the outside to the inside stands at $1.25: 1: 4$. It is noted that the heat flux transferring from the outside to the inside accounts for the main part; the ratio of the heat flux in the other two processes is almost the same.

(3) According to the different state of the indoor and outdoor thermal environment in different running states of the air-conditioning system, the direction of the heat flux transferring through the wall also presents dynamic changing characteristics. Besides, in different air-conditioner's running state, the ratio of heat flux in each direction is different. But to sum up, in summer in this region, under any air-conditioner running state, the main directions of the heat flux through the wall are mainly from the outside to the inside in daytime and during night time, mainly from 
the internal of the wall to the outdoor and indoor surface of the wall (or from the inside to the outside). Therefore, it can be concluded that, under any airconditioner's running state in summer in this region, the thermal performance demand of the wall is that it has strong demand for thermal insulation in daytime and strong demand for heat dissipation during night time.

(4) Future work will carry out tests in winter and transitory periods (autumn and spring). By analyzing the whole year testing results, the requirements of the building wall energy savings (which is also the core object for energy savings) in this region can be obtained. Thus, this work can provide fundamental theory basis for suitable configuration design of the wall in this region (Suitable configuration design of the wall for this region means in accordance with the characteristics of the thermal process through walls in this region, by improving the main body and insulation materials of the wall, optimizing insulation layer distribution and thickness and other means to meet the insulation and heat dissipation needs of the wall).

\section{Conflict of Interests}

The authors declare that there is no conflict of interests regarding the publication of this paper.

\section{Acknowledgment}

The Central Universities Research Funds for Science Class Interdisciplinary Projects (CDJZR12 2155 01) are gratefully acknowledged for funding this research.

\section{References}

[1] X. Z. Fu, Y. Feng, and J. H. Peng, Building Energy-Saving Technology in Hot Summer and Cold Winter Zone, China Architecture \& Building Press, 2002 (Chinese).

[2] A. Praditsmanont and S. Chungpaibulpatana, "Performance analysis of the building envelope: a case study of the Main Hall, Shinawatra University," Energy and Buildings, vol. 40, no. 9, pp. 1737-1746, 2008.

[3] D. H. C. Chow, Z. L. Li, and J. Darkwa, "The effectiveness of retrofitting existing public buildings in face of future climate change in the hot summer cold winter region of China," Energy and Buildings, vol. 57, pp. 176-186, 2013.

[4] L. Yang, J. C. Lam, and C. L. Tsang, "Energy performance of building envelopes in different climate zones in China," Applied Energy, vol. 85, no. 9, pp. 800-817, 2008.

[5] P. Tummu, S. Chirarattananon, V. D. Hien, P. Chaiwiwatworakul, and P. Rakkwamsuk, "Thermal performance of insulated walls enclosing residential spaces in Thailand," Energy and Buildings, vol. 61, pp. 323-332, 2013.

[6] F. Wu and J. Zhu, "Study on the construction of the database of energy-saving building walls thermal performance in Hangzhou," Energy Procedia, vol. 14, pp. 943-948, 2012.
[7] Z. Yang, Y. Zhao, X. Xu, and B. Zhai, "Analysis and comparison of building energy saving reconstruction in hot summer and warm winter regions of South China and cold regions of North China," Energy and Buildings, vol. 54, pp. 192-195, 2012.

[8] S. Hori, K. Kondo, D. Nogata, and H. Ben, "The determinants of household energy-saving behavior: Survey and comparison in five major Asian cities," Energy Policy, vol. 52, pp. 354-362, 2013.

[9] N. N. Kang, S. H. Cho, and J. T. Kim, "The energy-saving effects of apartment residents' awareness and behavior," Energy and Buildings, vol. 46, pp. 112-122, 2012.

[10] DBJ50-071-2010, "Design Standard for Energy Efficiency 65\% of Residential Buildings in Chongqing," Chongqing Construction Technology Development Center, Chongqing Municipal Building Energy Conservation Center, 2010.

[11] JGJ132-2009, Inspection Standard for Building Energy Efficiency in Residential Buildings, China Academy of Building Research, 2009.

[12] GB/T 18204 13-2000. Measurement Method for Air Temperature in Public Places, Health and Epidemic Prevention Station in Jilin Province, 2001.

[13] GB/T 18204 14-2000, "Measurement Method for Air Humidity in Public Places, Health and Epidemic Prevention Station in Jilin Province," 2001.

[14] GB/T 11605-2005, "Measurement Method for Humidity, Chengdu Instrument Factory," 2001.

[15] H. H. Wang, G. M. Zhou, and X. Y. Li, Heat Transfer, Congqing University Press, Chongqing, China, 2006, (Chinese).

[16] S. Tian and Y. Xiao, Experimental Design and Data Processing, China Architecture \& Building Press, 1996, (Chinese).

[17] J. P. Holman, Heat Transfer, China Machine Press, Beijing, China, 2008.

[18] Q. S. Yan and Q. Z. Zhao, Building Thermal Process, China Architecture \& Building Press, 1986.

[19] S. Al-Sanea, M. F. Zedan, and S. N. Al-Hussain, "Effect of thermal mass on performance of insulated building walls and the concept of energy savings potential," Applied Energy, vol. 89, no. 1, pp. 430-442, 2012. 

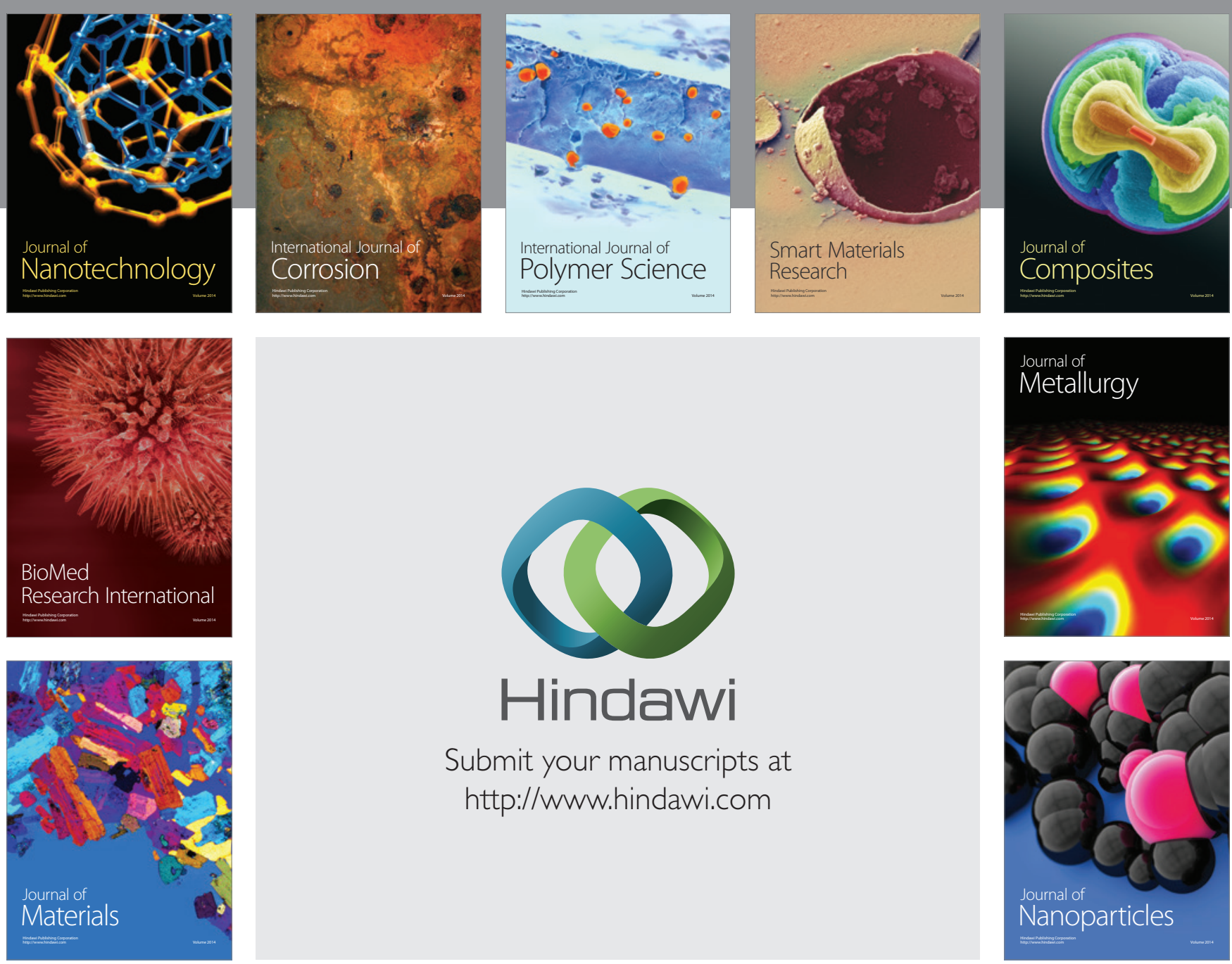

Submit your manuscripts at http://www.hindawi.com
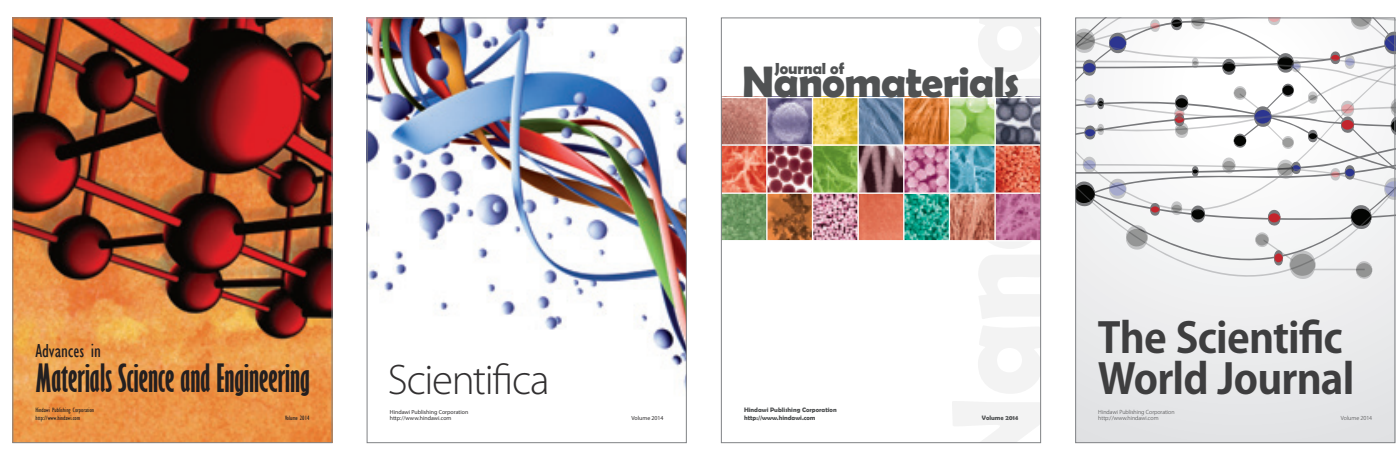

\section{The Scientific World Journal}
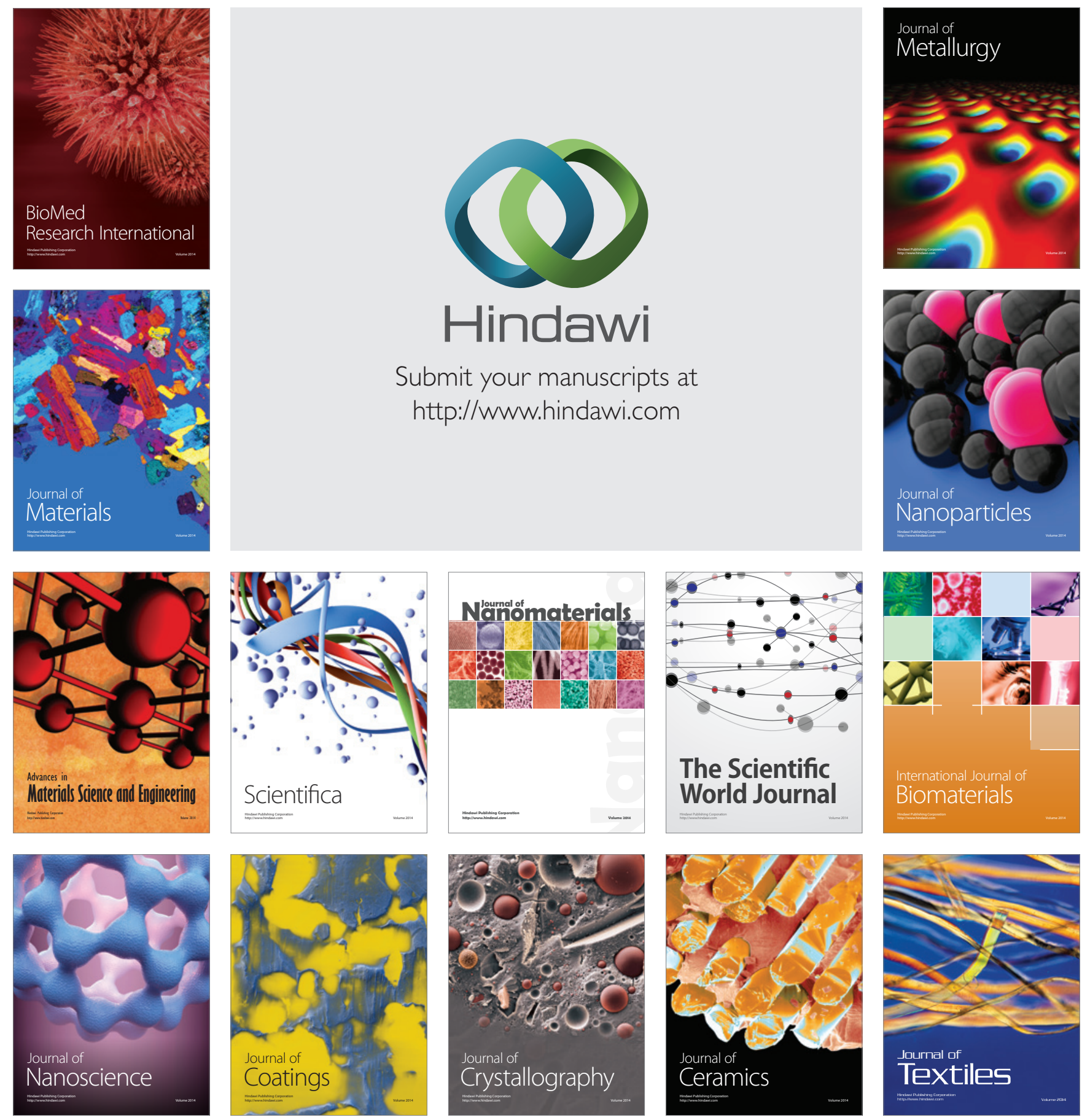